\title{
LAS FUNCIONES INTERCONSTITUCIONALES DEL JEFE DEL ESTADO PARLAMENTARIO
}

\section{The constitutional functions of the parliamentary head of State}

\author{
MIGUEL HERRERO DE MIÑÓN \\ Real Academia de Ciencias Morales y Políticas \\ Miguel.HerreroMinon@consejo-estado.es
}

Cómo citar/Citation

Herrero de Miñón, M. (2017).

Las funciones interconstitucionales del jefe del Estado parlamentario.

Revista Española de Derecho Constitucional, 110, 13-42. doi: https://doi.org/10.18042/cepc/redc.110.01

Resumen

El parlamentarismo consiste en que el Gobierno se basa en la confianza de la mayoría de la Asamblea y es controlado por esta. Las funciones del jefe del Estado parlamentario han evolucionado desde el parlamentarismo dualista donde el Gobierno necesita la doble confianza de la Asamblea y del jefe del Estado (orleanismo) a su debilitación e, incluso, desaparición y, después, a un fortalecimiento con competencias arbitrales hasta llegar al semipresidencialismo. Actualmente, la Jefatura del Estado parlamentaria es relevante por su supremacía de posición, su participación indirecta en la supremacía de gobierno y su condición de magistratura de garantía.

\section{Palabras clave}

Jefatura de Estado; Parlamento; responsabilidad; veto; semipresidencialismo; disolución. 


\begin{abstract}
The parliamentary system of government signifies the executive's permanent accountability in which the Head of State become just a symbol or even it disappears, and again a powerful institution vested with arbitral competences (semipresidentialism). Nowadays, the parliamentary Head of State is a relevant institution for its "dignified position" in the constitutional framework, for its indirect participation in the government, as adviser of its own councelors (the ministers) and as a guarantee of the constitutional procedures and values: the to the Assembly. The role of the parliamentary Head of State changes from a dualistic system in which the Government needs both the confidence of the Assembly and the Head of State, to a monistic system peoples' sovereignty and the respect of minorities.
\end{abstract}

\title{
Keywords
}

Head of State; Parliament; accountability; semipresidentialism; veto; dissolution. 


\section{SUMARIO}

I. ¿̇ES ÚTIL LA INSTITUCIÓN DE LA JEFATURA DEL ESTADO EN UNA DEMOCRACIA PARLAMENTARIA? II. LA EVOLUCIÓN DEL PARLAMENTARISMO. EL SEMIPRESIDENCIALISMO. III. LOS PODERES DEL JEFE DEL ESTADO: 1. Supremacía de posición. 2. Supremacía de mando. 3. Defensa de la constitución: 3.1. Prerrogativa regia británica. 3.2. Semipresidencialismo. 3.3. La práctica belga e italiana como ejemplos típicos del parlamentarismo «clásico». IV. CONCLUSIONES. Bibliografía.

\section{I. ¿¿ES ÚTIL LA INSTITUCIÓN DE LA JEFATURA DEL ESTADO EN UNA DEMOCRACIA PARLAMENTARIA?}

La esencia del parlamentarismo consiste en que el encargado del Gobierno debe contar con la confianza de la Asamblea representativa y, en virtud de su decantación y evolución histórica, al Gobierno parlamentario se superpone otra institución como órgano supremo del Estado: su jefatura. Ahora bien, la doctrina constitucionalista lleva un siglo preguntándose por la necesidad de tal institución y ha llegado a impugnarla sin que falten formas de parlamentarismo acéfalas de las que después daré muestras. Esto es, sin jefe del Estado. Tras las huellas de Kelsen ${ }^{1}$, los alemanes Kimminich ${ }^{2}$ y Ehmke entre otros, seguidos brillantemente en España por el profesor de Sevilla, Javier Pérez Royo ${ }^{4}$, han planteado clara y rigurosamente la cuestión para responderla en sentido negativo.

A su juicio, la Jefatura del Estado en la democracia parlamentaria es una reliquia de fases políticas ya superadas que solo por inercia o por circunstancias transitorias de oportunidad se conserva en numerosos países. Pero las funciones con que se ha tratado de justificarla no resisten la crítica. Lo que desde Benjamin Constant se llamó «poder neutro», esto es, el juez de los otros poderes, es incompatible con el dogma democrático de la unicidad de la soberanía popular; su supuesta representación de la unidad del demos no responde

1 Kelsen (1979: 393). Sobre la posición de Kelsen de cara a sus primeras construcciones positivas, las iniciales constituciones austríacas de postguerra, véase Kelsen (1919).

2 Kimminich (1967: 48).

3 Ehmke (1953: 239)

4 Pérez Royo (1984: 7). 
al pluralismo de este y desplaza la representatividad parlamentaria; su condición de órgano de representación internacional del Estado es un tanto secundaria y depende más bien del derecho internacional y solo por remisión de este a las diferentes opciones constitucionales estatales. Más aún, las funciones típicas de la Jefatura del Estado pueden distribuirse entre otras de sus instituciones sin mengua de su eficacia; y no faltan constituciones que sirvan de ejemplo. Tal es el caso del Instrumento de Gobierno sueco de 1974.

A ello se añade la muy extendida interpretación del parlamentarismo, según la cual, el sistema evoluciona, necesaria y linealmente, desde fórmulas dualistas en las que el jefe del Estado desempeña una función activa, a fórmulas monistas en la cuales lo único políticamente relevante es la relación entre la Asamblea y el Gobierno; y la Jefatura del Estado se convierte en «un sillón vacío», cuya «racionalización» exige su supresión.

A mi entender, tan brillantes tesis olvidan extremos fundamentales que desmienten la citada evolución y avalan la utilidad e, incluso, la necesidad del jefe del Estado parlamentario. A demostrarlo se dirige el resto de mi ponencia.

La merecida autoridad de los tres autores citados, la relevancia de la cuestión y la altura de su argumentación requieren que inicie la mía con un cordial saludo de cortesía, especialmente dirigido al docto profesor sevillano. Y evitaré referencias a la génesis y evolución de la Jefatura del Estado en la vigente Constitución española, por cierto, la única en Europa que califica de «parlamentaria» la monarquía. Esta es una disertación académica, no un alegato político, sin que ello obste a que una política sensata debiera prestar atención a lo que digan los académicos.

\section{LA EVOLUCIÓN DEL PARLAMENTARISMO. EL SEMIPRESIDENCIALISMO}

Comenzaré examinando la evolución histórica del moderno parlamentarismo. Su esencia consiste, como antes dije, en que el encargado del Gobierno, llámese como se llame, debe contar con la confianza de la Asamblea representativa y ser controlado por esta. Eso y no otra cosa es el parlamentarismo. De ahí que surjan diferentes versiones neo de la instrumentación del principio parlamentario, si bien no me ocuparé de ellas en este ensayo5. Y que, a la inversa, a la búsqueda de precedentes, no falten historiadores que, con razón, han visto un régimen parlamentario en las «libertades suecas», cuando, desde

5 Herrero de Miñón (1971: 121). 
1729, los cuatro estamentos elegían en la Dieta al Consejo que asistía al rey ${ }^{6}$ o en el Gobierno revolucionario de la I República Francesa por el Comité de Salud Pública, elegido y solo responsable ante la Convención Nacional'. Incluso el docto obispo Stubbs ${ }^{8}$, calificó, en 1898, de preparlamentario el Gobierno de los últimos Lancaster. El parlamentarismo se opone, así, radicalmente al presidencialismo o cualquier otra forma de desconexión entre el ejecutivo y el legislativo. Utilizando las categorías de Loewenstein ${ }^{9}$, mientras el parlamentarismo imbrica órganos horizontales de control, el presidencialismo los separa y hace complementarios. Ello debiera ser tenido en cuenta por quienes exigen una rigurosa separación de poderes a la vez que alaban el sistema parlamentario.

Sabido es que el parlamentarismo surge - aquende tales precedentes, en el seno de la monarquía, en Gran Bretaña primero, en el continente después - para compatibilizar la autoridad del rey hereditario con el Gobierno representativo. En una primera fase, el parlamentarismo es dualista y el Gobierno requiere, expresa o tácitamente, la doble confianza del jefe del Estado y de la o las asambleas y el primero tiene el derecho de disolución de las segundas. Es el parlamentarismo denominado orleanista, porque, aun gestado en la Restauración francesa, se consolidó bajo la Monarquía de Julio ${ }^{10}$.

Muchos años después, cuando, salvo en España donde el dualismo estuvo en vigor hasta 1931, ya el sistema basculaba desde el dualismo hacia el monismo, Redslob ${ }^{11}$, en un libro famoso publicado en 1918, se hizo eco de las críticas formuladas en 1903 por Duguit ${ }^{12}$ a la práctica constitucional de la III República Francesa y calificó el dualismo de parlamentarismo auténtico frente al «falso parlamentarismo» monista. Una vez más, la académica lechuza de Minerva volaba al son de Completas, pero fueron las tesis de Redslob las que inspiraron a Hugo Preuss al diseñar la Constitución alemana de Weimar que, como mostraré más adelante, inició la recuperación del parlamentarismo dualista.

6 Carlsson y Rosén (1961: 96). Sobre el panorama comparado, véase Herrero de Miñón (1986: 309).

7 Mirkine Guetzevitch (1935: 671).

8 Stubbs (1898: 5).

9 Loewenstein (1965: 103). Sobre la posición del jefe de Estado, en general, véase Loewenstein (1949) y Kaltefleiter (1970).

10 Díez del Corral (1998: 195).

11 Redslob (1918). Sobre la influencia de esta obra en los redactores del texto de Weimar a la que después haré referencia, véase Lukas (1920).

12 Duguit (1903). 
El parlamentarismo monista, esto es, aquel en el que el Gobierno depende principalmente de la confianza de la Asamblea y no de la confianza regia, se abre paso merced a la técnica del refrendo ministerial de los actos regios. Cualquiera que sea su origen, el refrendo ministerial se convierte en el instrumento para cubrir la irresponsabilidad política del jefe del Estado, substituyéndola por la del ministro refrendante que responde políticamente ante la Cámara cuya confianza necesita para gobernar; y sabido es que poder y responsabilidad van unidos.

Las leyes constitucionales de la III República Francesa de 1873-1877, establecieron un sistema "orleanista» en espera de una pronta restauración monárquica, pero, a la vez, lo hicieron de acuerdo con una versión whig del parlamentarismo británico entonces de $\operatorname{moda}^{13}$ y abrieron la puerta a la primacía de la Asamblea Nacional sobre el presidente de la República, una fórmula que, como antes dije, el gran León Duguit criticó acerbamente como «falso parlamentarismo». La figura del presidente de la República parlamentaria se esfumó progresivamente frente a la del Gobierno responsable ante la Asamblea Nacional, la exigencia de refrendo ministerial debilitó el derecho presidencial de disolución y el veto suspensivo sobre las leyes. Y durante la

13 La última y más popular muestra del constitucionalismo whig es la conocida obra de Bagehot (1867), antes de cuya 2. a edición, en 1872, hubo dos tempranas traducciones francesa y alemana. La primera, publicada en la prestigiosa Bibliotheque d"Histoire Contemporaine (Paris, 1868) con la intención de arropar doctrinalmente y con el prestigio de las instituciones británicas, los proyectos de parlamentarización al amparo de la última Constitución del II Imperio del mismo año (Senados consulta de 8 de septiembre de 1869 y 21 de mayo de 1870). Prévost-Paradol (1868), epígono del doctrinarismo y que se había destacado en la oposición al autoritarismo bonapartista, antes de suicidarse en 1870, se convirtió en defensor del II Imperio y de su evolución liberalizadora, propugnando un parlamentarismo compatible con la monarquía imperial. De ahí su reiterada mención en el inusitado prólogo de Bagehot a la edición francesa de su obra. La traducción alemana (Berlin, 1868), del mismo signo liberal, no tuvo, desgraciadamente, fortuna frente a los defensores germánicos del principio monárquico, véase Jellinek (1980: 516). Sobre la versión francesa, Posada hizo una traducción española publicada en 1902, tal vez con una análoga intención pedagógica respecto del joven rey Alfonso XIII, recientemente proclamado mayor de edad. Que Posada no utilizó el original inglés, sino la traducción francesa, lo revelan ciertas equivalencias, v. gr. traducir dignified parts por "partes imponentes» (p. 47) tomado de «imposants parts» (p. 68) y que no utilizara la segunda edición inglesa de 1872. Sobre la proyección española de la obra de Bagehot, véase el docto estudio preliminar de Varela Suanzes-Carpegna (2010) a la reedición de la traducción española de Posada, de Madrid (CEPYC). 
I Guerra Mundial y a la hora de la paz, la primacía del presidente del Consejo, Clemenceau, sobre figura tan prestigiosa como Poincaré, presidente de la República, mostró la debilidad de la Jefatura del Estado parlamentaria, como señaló en escritos autobiográficos el mismo presidente ${ }^{14}$.

La experiencia política francesa pesó en lo que Mirkine Guetzevitch denominó «Las Constituciones de la Nueva Europa»" ${ }^{15}$, posteriores a la I Guerra Mundial. Así se puso de manifiesto en diferentes procesos constituyentes de las nuevas repúblicas de Europa central y oriental, iniciados por constituciones provisionales que establecen gobiernos de asamblea. La doctrina, a la luz de la estrella ascendente de Hans Kelsen, avaló la debilitación de la Jefatura del Estado e, incluso, su desaparición. Surgen, así, con pretensiones de definitivas en los Länder alemanes, parlamentarismos sin jefe del Estado ${ }^{16} \mathrm{y}$ en dos repúblicas bálticas, Estonia y, hasta cierto punto, también Letonia, parlamentarismos monistas en los que el presidente de la República, un efectivo dirigente del Gobierno, es elegido por la Cámara y responsable ante ella ${ }^{17}$.

El emergente constitucionalismo soviético que propugnaba la provisionalidad del Estado, sustituido por el autogobierno de los consejos, siguió la misma línea. A ello me referiré después con más detalle ${ }^{18}$.

Donde se conserva un ejecutivo bicéfalo, con jefe del Estado y primer ministro, se debilita al primero en favor del segundo. Así, la primera Constitución austríaca, obra del propio Kelsen, rechazada la idea inicial de un sistema directorial análogo al helvético, estableció un régimen de asamblea con un ejecutivo elegido y responsable ante ella y un presidente elegido cada cuatro años por la misma Asamblea e investido de potestades meramente honoríficas. En Polonia, la Constitución de 1921 recortaba muy mucho las competencias de jefe del Estado y otro tanto ocurrió en Lituania con la Constitución de $1922^{19}$.

Tales sistemas no soportaron, a partir del inicio de los años veinte, lo que Keynes había anunciado como "Las consecuencias económicas de la paz», dobladas con la agudización de los conflictos nacionales fomentados por los

14 Deux lettres au sujet du rôle du President de la République, Le Temps, 9 y 25 de agosto de 1920. Véase Röpke (1922).

15 Mirkine Guetzevitch (1928) y Mirkine Guetzevitch (1931).

16 V. gr. Baviera (1919: 4, 57 y 58) y Prusia (1920: arts. 7, 44 y 45). Véase Kollreutter (1921).

17 Véase Estonia (1920: arts. 58 y 59). Véase Rolnik (1927).

18 La bibliografía sobre la teoría soviética del Estado y de su futura extinción es inmensa. Como muestra, véase Zolo (1974). En español es útil García Álvarez (1978: 37).

19 Poyulicki (1921) y Rolnik (1927). 
Tratados de Versalles y del Trianon. En pocas palabras, crisis, inestabilidad y temor a la expansión de la revolución soviética. A los regímenes de asamblea sucedió por doquier lo que Michel Dendias ${ }^{20}$ denominó el fortalecimiento de los poderes del jefe del Estado, no del Gobierno, en las democracias parlamentarias.

Así, en Checoeslovaquia — que, por influencia kelseniana, había contemplado en 1919 un proyecto constitucional inspirado en el modelo suizo, esto es, un Gobierno directorial elegido y responsable ante la Asamblea- se estableció, ya en 1920, una Constitución con un Ejecutivo bicéfalo directamente inspirado en la III República Francesa, pero donde se reforzaba la Jefatura del Estado, cuya influencia no dejó de $\operatorname{crecer}^{21}$. Y el modelo alemán de Weimar de 1919, cuyo autor Hugo Preuss, siguiendo las tesis del citado Redslob sobre el auténtico parlamentarismo, había equilibrado la Dieta con un presidente elegido directamente por el pueblo e investido con importantes competencias como el nombramiento del Gobierno, la disolución de la Asamblea, la convocatoria del referendo y la legislación de urgencia, inspiró la nueva Constitución lituana de 1928 y, muy especialmente, la reforma austríaca de 1929. Incluso la Constitución española de 1931, cuyos críticos señalaron la debilidad de la Jefatura del Estado ante las Cortes, configuró una presidencia de la República dotada de poder propio, fundamentalmente y por clara influencia de Weimar, el nombramiento del presidente del Gobierno $^{22}$.

Al hilo de esta evolución constitucional se fue decantando la autonomía institucional de la Jefatura del Estado frente al Gobierno y viceversa. Lo primero supone la exclusión de los poderes propios del jefe del Estado de la exigencia del refrendo ministerial y lo segundo se concreta en la atribución al Gobierno de potestades ejecutivas, ajenas formal y substancialmente a la intervención del jefe del Estado. Más adelante insistiré y aclararé este extremo.

Semejante movimiento pendular en favor de la Jefatura del Estado llegó al límite del abandono del parlamentarismo. Las reforma constitucional polaca de 1926, fruto del denominado pilduskismo, condujo al sistema cuasiautoritario consagrado en la Constitución ultrapresidencial de 1929; y la austriaca de 1934 previó un sistema autoritario y corporativo inspirado en

20 Dendias (1932).

21 Vernet (1922); para la ulterior evolución política y consiguiente mutación constitucional, véase Peska (1930).

22 Robinson (1928), Mirkine Guetzevitch (1930) y Alcalá-Zamora y Torres (1936: 143). 
el fascismo italiano (leyes de 1925 a 1939), a su vez, inspirador de la Constitución portuguesa de 1933, centrada en los poderes del presidente de la República, si bien dirigida en la práctica por el jefe del Gobierno responsable solamente ante aquel ${ }^{23}$.

Como, al examinar el constitucionalismo de su época, puso de relieve el comparatista Ezequiel Gordon ${ }^{24}$, las monarquías parlamentarias siguieron la misma tónica. Ya de hecho, al volver o, mejor, acentuar en la práctica al parlamentarismo dualista, por ejemplo, en Rumanía bajo la Constitución de 1926, ya de derecho, con fórmulas constitucionales autoritarias. Así, en 1929, el golpe de estado regio impuso la dictadura en Yugoslavia; años después se proclama la Constitución autoritaria de 1938 en Rumania que establece una diarquía entre el monarca y el jefe del Gobierno. Por las mismas fechas, en España, el general Primo de Rivera hizo elaborar un proyecto constitucional que, frente al parlamentarismo dualista decantado bajo la Constitución de 1876, reforzaba el Ejecutivo basado en la sola confianza regia ${ }^{25}$.

El fracaso de los excesos de parlamentarización condujo a lo que Barthélemy calificó de "crisis del parlamentarismo»; y la excesiva racionalización del poder que pretendía sustituir la política por el derecho procesal abrió la puerta a lo que, en famoso título, Paul Barres había denominado «la entronización del guerrero" (L'appel au soldat).

Tras la II Guerra Mundial, dos experiencias paralelas y contradictorias que marcaron el fin de una época, determinaron la reconfiguración constitucional de la Jefatura del Estado. Por una parte, la experiencia francesa de 1940 que mostró las carencias del poder presidencial de la III República; por otro lado, la crisis del sistema de Weimar en 1933, por la interpretación ultrapresidencial que a su práctica dieran Hindenburg y sus acólitos. Ambas contribuyeron a radicalizar los planteamientos democráticos en la inmediata posguerra, pero ambas mostraron que la defensa de la Constitución democrática no podía quedar en manos solo del Parlamento.

En el campo de la Resistencia francesa, abundaron los proyectos en tal sentido que habían de cristalizar en el discurso gaullista de Bayeux (1946), un antecedente doctrinal de la Constitución francesa de 1958. Pero la IV

23 Trentin y Bonnecase (1929). Véase Ghisalberti (1974: 23). Respecto de Polonia (1934: arts. 1-25) y especialmente la definición que de la institución da el art. 1; Portugal (1933: arts. 72, 78, 81 y 82).

24 Gordon (1931: 311).

25 Con más detalle, véase Jovanovitch (1930). Respecto de España, los textos en Varela Suanzes-Carpegna (2012: 375) y una síntesis del contexto en Fernández Segado (1986: 418). 
República se organizó en sentido contrario sobre la radicalización del principio parlamentario. La Constitución de 1946 fue un fruto tardío y extemporáneo de la época anterior; $y$, abocada desde su nacimiento al fracaso, sirvió de vacuna a las siguientes experiencias constitucionales europeas.

Así, el mal recuerdo de Weimar, llevó en la nueva República Federal alemana a la reacción proparlamentaria y procancilleral de la Ley Fundamental de Bonn. Pero tanto esta como, sobre todo, la Constitución italiana de 1948 reconocen la importancia funcional de la Jefatura del Estado.

Ello es evidente en los debates de la constituyente italiana de 1947 que decanta la noción de poderes propios del presidente de la República, reconoce lo que en los mismos debates y en su exégesis doctrinal se denominó expresamente la «prerrogativa presidencial» y ello da lugar a la ambigua configuración y más ambigua interpretación del refrendo en el art. 89 del texto definitivo. Una ambigüedad que se ha ido disipando mediante la progresiva expansión de las competencias presidenciales por mutación constitucional $^{26}$.

Por su parte, la Ley Fundamental alemana, aunque limita muy mucho las competencias presidenciales con relación al texto de 1919, se hace eco de la polémica doctrinal abierta en la década anterior. Por ello, excluye del refrendo ministerial las competencias presidenciales que considera eminentemente arbitrales (art. $58 \mathrm{GG}$ ) y, de acuerdo con un principio general del derecho germánico, abre el paso a un fortalecimiento de derecho de examen del presidente antes de formalizar una serie de actos de Estado. Desde el nombramiento de altos funcionarios hasta la promulgación de las leyes, pasando por la ratificación de tratados internacionales y los decretos gubernamentales. Pero, además, una cuidadosa interpretación de los arts. 63,3, 67, 68 y 81 GG pudiera dar lugar a la hipótesis de un Gobierno dotado de competencias legislativas, fundado en la sola confianza del presidente federal ${ }^{27}$.

Es en esta circunstancia, que Pocock y la escuela historiográfica de Cambridge denominarían «momento», cuando, hasta el propio Mirkine Guetzevitch $^{28}$ está de vuelta de ingenuidades pacifistas y racionalizadoras, en la que la V República Francesa de 1958 abre nuevas vías al constitucionalismo. Sabido es que la Constitución ultraparlamentaria de 1946 — si bien no impidió el desarrollo económico y social de Francia y la consolidación de una Administración que, como en tiempos de Tocqueville, Europa sigue envidiando- dio paso a una inestabilidad política todavía mayor que la

\footnotetext{
26 Caporali (1999: 11).

27 Una síntesis de la doctrina alemana sobre la materia en Leissner (1958: 65).

28 Mirkine Guetzevitch (1952).
} 
característica de las postrimerías de la III República, incapaz de gestionar la política exterior y, en especial, los problemas de la descolonización. El general De Gaulle, investido de la legitimidad carismática del 18 de junio de 1940, asumió el poder y elaboró una nueva Constitución, la de 1958, donde es evidente la herencia de Weimar y que está en la génesis de lo que se ha denominado semipresidencialismo ${ }^{29}$.

Se entiende por tal aquel sistema que mantiene el régimen parlamentario, como atrás lo definí, la responsabilidad política del Gobierno ante la Cámara, junto con una Jefatura del Estado ajena a las Cámaras parlamentarias e investida de efectivas competencias propias, de finalidad moderadora y arbitral. Tal es el sistema hoy vigente, además de la V República Francesa, en otros muchos Estados: Finlandia (1997, desde 1919), Austria (1926), Irlanda (1937), Islandia (1947), Portugal (1974) y Grecia (1975). Las nuevas repúblicas democráticas de Europa central y oriental también han establecido, a partir de 1991, regímenes semipresidenciales, en Polonia, Croacia, Rumanía, Bulgaria, Serbia, Eslovenia, Eslovaquia y Lituania.

Maurice Duverger, inventor de tan afortunado término ${ }^{30}$, consideró fundamental característica del semipresidencialismo la elección del jefe del Estado por sufragio universal directo. Las abundantes críticas a tan simplista caracterización insisten en tres extremos importantes ${ }^{31}$.

Por un lado, la legitimación del jefe del Estado por el sufragio directo no es exclusiva ni excluyente y con ella pueden concurrir otras fuentes de legitimación capaces de sumar o restar a la posición del presidente. Pendiente también, y en ello consiste el segundo extremo olvidado por Duverger, de la cambiante situación del escenario político y de la tradición político-constitucional de cada Estado. No es lo mismo que el presidente, elegido por sufragio universal directo, sea heredero del emperador alemán, como ocurría en la Constitución de Weimar, que, del lejano rey de Dinamarca, como es el caso de Islandia. Y, por último, aun aceptando la caracterización de Duverger, las competencias presidenciales pueden ser muy variadas, como muestran los casos extremos de

29 Duverger (1986). Esa influencia se debe, principalmente, a la doctrinal que Schmitt ejerció sobre René Capitant, uno de los constitucionalistas de cámara del general De Gaulle: véase Le Brazidec (1998).

30 Duverger (1970).

31 Colliard (1978: 39). El análisis, a todas luces sectario, pero extremadamente detallista de Gicquel (1968) revela, tal vez incluso, frente a la intención del autor, que la preponderancia presidencial se dio, desde el principio, en virtud de carisma gaullista, al margen de la elección del jefe del Estado por sufragio directo, establecida en 1962. 
Francia e Irlanda y, de ahí, que el propio autor deba distinguir entre semipresidencialismos de práctica parlamentaria y de práctica semipresidencia ${ }^{32}$.

A mi juicio, en un orden racional-normativo como el que es propio de los Estados constitucionales a los que este ensayo se refiere, la legitimación de las instituciones tiene su base en la propia Constitución y no en la dinámica popular. El pueblo legitimó la Constitución, pero esta y solo esta, mientras está vigente, es la que atribuye y distribuye las competencias en las instituciones que crea o relegitima. Por eso, el rey, igual que un presidente, se legitima no por su origen histórico o electivo, sino por la propia normatividad de la Constitución. Lo otro corresponde a lo que M. Fioravanti ${ }^{33}$ denomina «modelo constitucional radical», lejano al que ha regido y rige en Occidente.

En consecuencia, lo decisivo en el semipresidencialismo no es la elección popular del jefe del Estado, sino sus poderes propios ${ }^{34}$. Esto es, aquellos que se le atribuyen, no solo formal sino efectivamente y que en consecuencia llegan a ejercerse sin refrendo del Gobierno parlamentario o haciendo de este una institución prácticamente auxiliar de la Presidencia y del refrendo, no un instrumento de control, sino de garantía de cumplimiento. Grecia desde 1975 y, desde 1991, la República Checa y las repúblicas bálticas atribuyen importantes poderes propios al presidente sin perjuicio de su elección parlamentaria.

Como señalaron los trabajos preparatorios de la vigente Constitución croata de $1990^{35}$, el semipresidencialismo tiene mucho de retorno al «parlamentarismo dualista» — la citada Constitución croata establece expresamente la exigencia de doble confianza presidencial y parlamentaria del Gobierno (art. 111) - que Redslob calificara de "auténtico» y en su evolución cabe señalar tendencias ya incoadas en tales precedentes.

Por una parte, el semipresidencialismo supone un equilibrio dinámico y así el francés ha evolucionado convencionalmente en sentido presidencial ${ }^{36}$ y el portugués en sentido parlamentario poniendo freno, desde la reforma constitucional de 1982, al ultrapresidencialismo, hacia el que había derivado la práctica constitucional, sin que en ningún caso se haya renunciado, antes al contrario, a

32 Duverger (1986: 8 y 12). Véase infra nota 38.

33 Fioravanti (2002: 74).

34 Francia (1958: art. 19); Grecia (1975: art. 35); República Checa (1991: art. 63.3); Bulgaria (1991: art 102); Rumanía (1991: art 100); Lituania (1991: art 85); Polonia (1997: art. 144) y Finlandia (1997: art. 58).

35 Véase el discurso del presidente F. Tudjman el 22 de diciembre de 1990 ante el Parlamento croata con ocasión de la proclamación de la Constitución (Rapport du Parlement, núm. 15).

36 Vedel (1964: 20). 
la autonomía institucional ni del presidente ni del Gobierno parlamentariamente responsable, cuyas competencias se reconocen expresamente ${ }^{37}$.

Por otro lado, si las primeras constituciones semipresidenciales fortalecen en exceso las competencias del jefe del Estado, las posteriores constituciones revelan una reacción proparlamentaria. Así lo muestra la comparación de los textos fineses de 1919, con la reforma de 1992 y el nuevo texto de 1997. Y las Constituciones de los más pequeños Estados, como Eslovenia, Eslovaquia, Estonia, Letonia, incluida la lituana, a más de la revisión portuguesa de 1982 antes citada. En Rumania, la Constitución de 1991 se califica por la doctrina como cuasisemipresidencial y la serbia del 2002 es claramente parlamentaria ${ }^{38}$.

Esta tendencia en pro de las competencias parlamentarias se extiende más allá de las relaciones con la Jefatura del Estado y, por ello, no cabe examinarla aquí. Uno de los grandes dilemas que se le presentan a la democracia de nuestros días radica en cómo mantener la estabilidad de un ejecutivo disciplinadamente apoyado por la mayoría de una Asamblea representativa y, a la vez, garantizar el eficaz control de esta y de sus representados sobre aquel. Lo que en la primera postguerra se denominó parlamentarismo racionalizado procuró lo segundo; con el mismo nombre, la Constitución francesa de 1958 y los sistemas que siguieron su ejemplo buscaron lo primero. Hoy se vuelve por los fueros de las asambleas, frente al peligro de un hipertrófico e incontrolado ejecutivo democrático. La Fixed-term Parliaments Act 1911 británica fue la más reciente, avanzada y significativa muestra de ello. Pero, incluso en este caso, el legislador que quiere limitar los poderes del primer ministro se muestra extremadamente prudente a la hora de erosionar los poderes regios de prerrogativa (véase sec. 6,1 de dicha ley). Una vez más, se muestra que la Jefatura del Estado no es el Ejecutivo; es algo distinto y superior.

La búsqueda del equilibrio entre lo que Duverger llama las versiones proparlamentarias y propresidenciales del semipresidencialismo tiene su mejor exponente en la participación de la Jefatura del Estado en la designación del Gobierno. Desde el inicio del fortalecimiento de aquella en el texto de Weimar, quedó claro que las principales competencias presidenciales eran — junto con el derecho de disolución y, en su caso, la convocatoria de un referendo y el planteamiento de cuestiones de constitucionalidad ante la jurisdicción ad

37 Gomes Canotilho y Moreira (1991).

38 Gutan (2012: 275) destaca las diferentes actitudes del pasivo presidente Constantinescu y del activo presidente Besescu que avalan la distinción de Duverger entre semipresidencialismo de práctica parlamentaria y de práctica presidencial (véase supra nota 32). La correspondiente tensión llega a tener un reflejo jurisprudencial. Véase Selejn-Gutan (2016). 
hoc - la designación del canciller y, a través de él, del Gobierno todo, frente a la fórmula, atrás expuesta, de su elección por la Asamblea. El lógico temor a que unas sucesiones de gobiernos presidenciales eliminaran de hecho el régimen parlamentario, como ocurrió en los últimos años de la República de Weimar, llevó a los constituyentes alemanes de 1948 a idear un sistema mixto (art. 63 GG). El presidente federal designa un candidato a la Cancillería que la Dieta elige por la mayoría absoluta, sin debate. Si no se reúne dicha mayoría ni la Dieta elige otro canciller ni, días después, se obtiene una mayoría simple, el presidente disuelve el Parlamento o nombra al más votado.

La fórmula trata de compaginar la primacía de la opción de la Dieta con una iniciativa formal del jefe del Estado y con una intervención arbitral de este en caso de bloqueo parlamentario. Dicha fórmula ha tenido influencia en las Constituciones nuevas y reformadas, tanto monárquicas como republicanas. Entre las primeras, tal es el caso de la española de 1978 (arts. 99, 3, 4 y 5) alargando excesivamente los plazos y eliminando la competencia regia de desbloqueo y de la reforma belga de 1993. Entre las segundas, las de Grecia de 1975 (art. 36), de Eslovenia de 1991 (art. 111) y de Finlandia de 1997 (art. 61).

\section{LOS PODERES DEL JEFE DEL ESTADO}

Esta breve reseña del derecho y la práctica constitucional comparados nos permite trazar un cuadro bastante completo y fiel de las posibles competencias de un jefe del Estado parlamentario, sea monárquico o republicano.

Partamos, para ello, de las categorías acuñadas por un ilustre constitucionalista italiano, Esposito ${ }^{39}$, que, siguiendo la definición kelseniana de la Jefatura del Estado como uno de los órganos supremos de este - esto es, sin superior-, distingue tres tipos de supremacía: la de posición, la de mando y la de tutela.

\section{SUPREMACÍA DE POSICIÓN}

La supremacía de posición atribuye al jefe del Estado la primacía entre todas sus instituciones y en la sociedad que les da vida, con independencia de las competencias que cada Constitución le atribuya y que la costumbre y el protocolo se encargarán de subrayar. Que el primero en Francia sea el primero de los franceses, dijo René Coty, como eco de la Roma de Augusto, refiriéndose a De

39 Esposito, C. (1960). Capo dello Stato. Enciclopedia Italiana di Diritto, 6. 
Gaulle. Pasando desde tan elocuente anécdota a la categoría de que el primer magistrado sea también el primer ciudadano. Y esta primacía institucional y social sirve para hacer de la Jefatura del Estado lo que Smend ${ }^{40}$ denominó un factor de integración política, en un doble sentido.

Por un lado, y en función de las cualidades personales del titular de la magistratura, un factor personal de integración que actualiza formas más afectivas que racionales de legitimidad, bien sea tradicional (Isabel II en el Reino Unido, Aki Ito en el Japón), bien sea carismática (Mannerheim en Finlandia, De Gaulle en Francia). Una integración simbólica que la experiencia comparada demuestra, y las ceremonias y el ornato resaltan y fortalecen.

Cuando el jefe del Estado posee solo funciones simbólicas y de mera representación y formalización de actos procedentes de la voluntad de terceros, conserva esta supremacía de posición y, aun careciendo de toda competencia jurídica, es una magistratura reverenciada e influyente. Tal es el caso del emperador del Japón según la vigente Constitución de 1948 y del rey de Suecia según el Instrumento de Gobierno de $1974^{41}$. La comparación con presidentes de República en situación semejante, incluso elegidos por sufragio directo, por ejemplo, el presidente irlandés, muestra que el monarca hereditario garantiza mejor que el electivo la supremacía de posición. Los juristas y politólogos británicos consideran que es la experiencia acumulada a través de un largo reinado lo que fundamenta la influencia del monarca sobre el Gobierno parlamentario de turno ${ }^{42}$.

La Jefatura del Estado simboliza la identidad del Estado como tal Estado y no se requiere ser hegeliano confeso para reconocer en el Estado algo más allá de un mero organismo administrativo. Como decía el citado Smend, es algo que trasciende la producción de leyes, tratados, sentencias y actos administrativos. Más allá de las competencias jurídicas y del relieve político de la institución, la Jefatura del Estado significa, en un plano siempre ambiguo, pero innegable, la soberanía e infungibilidad del mismo Estado. De ahí que la Convención de Viena de 1969, sin perjuicio de remitirse a las Constituciones estatales, le presuma la condición de órgano central de representación internacional. Así resulta de la mayoría de las definiciones constitucionales de tal magistratura, tanto monárquicas como republicanas.

El realismo de tal definición lo prueba el que, cuando se quiere negar la condición estatal de una organización política, se elimina la Jefatura del Estado. Así ocurrió en los Países Alemanes (Länder) en 1919 y en 1948 al

40 Smend (1928), cuyas tesis sigo.

41 Rodríguez Artacho (2003).

42 Jennings (2959: 372). 
configurarlos sin Presidencia y otro tanto ocurrió en 1958 con los miembros de la Communauté francesa organizada por la V República, con la excepción de Madagascar, que nunca perdió la memoria de su estatalidad precolonial. Tal fue, también, el caso del constitucionalismo soviético y filosoviético, doctrinalmente orientados hacia la extinción del Estado y el Gobierno colegial. En la URSS, desde 1917; y, tras un breve período de transición hasta la consolidación del sistema (Hungría desde 1946 a 1949, Polonia desde 1947 a 1952 y RDA 1949 a 1960), en todas las Repúblicas Populares, salvo en Checoeslovaquia, que conservó la institución desde la primera de sus constituciones socialistas en 1948 hasta la de $1968^{43}$.

A la inversa, cuando los miembros de la Communauté acceden a la independencia en los años de 1959-1960, reforman sus instituciones para establecer Presidencias de la República; y las Repúblicas Populares en vías de emancipación se apresuraron, aún bajo la férula soviética, a restablecer sus Jefaturas de Estado. Primero en Yugoslavia desde 1953 que, bajo Tito, pronto comenzó su vía alternativa; después, en la Rumanía de Ceaucescu desde 1974; al final, en Polonia como símbolo de la restauración nacional, desde la reforma pactada de 1989, después incorporada a la «Pequeña Constitución de 1992» de donde pasa a la vigente de 1997. En la estirpe constitucional británica, el Irish Free State, once años antes de convertirse en República en 1948, quiso afirmar su condición de Estado soberano. Para ello, en la Constitución de 1937 sustituyó en la Jefatura del Estado al gobernador general, representante del monarca británico, por un presidente de Irlanda. Paralelamente, la estatalidad de los antiguos Dominions va de la mano con la divisibilidad de la Corona, expresada, a partir de 1953, en los títulos regios ${ }^{44}$.

El poder identificatorio de la Jefatura del Estado es tan grande que, incluso su forma, monárquica o republicana, tiene su trascendencia como expresión de estatalidad. La monarquía en Canadá, frente al poderoso vecino del sur, y la República en la India, que una vez independiente no podía tener un jefe de Estado extranjero, son buenos ejemplos de ello ${ }^{45}$.

Símbolo de la identidad estatal, es lógico que el jefe del Estado se esfuerce en aparecer como paradigma ético y estético del cuerpo político. No se trata de convertirlo en un museo viviente de las tradiciones, antes bien, debe representar los valores vigentes en la sociedad de su tiempo sin confundir la vigencia con la moda del instante y fomentando la solidaridad sentimental intergeneracional,

\footnotetext{
Brunner (1988: 2079).

Fawcett (1963: 1).

45 Véanse los datos y referencias reunidos en mi obra ya citada, Herrero de Miñón (1971: 529).
} 
base de la continuidad del Estado que su Jefatura expresa y garantiza, según afirman los textos constitucionales.

\section{SUPREMACÍA DE MANDO}

La supremacía de mando se atribuye al jefe del Estado parlamentario cuando este es parte del poder ejecutivo. Tal es el caso del clásico ejecutivo bicéfalo en el que el Gobierno se encomienda a un jefe del Estado, rey o presidente, asistido por un Gobierno colegiado, sea este el clásico gabinete o haya evolucionado hacia una forma cancilleral, siempre responsable ante la Asamblea y controlado por ella. Una fórmula paulatinamente superada a partir del texto italiano de 1948, mediante la progresiva autonomía de las dos instituciones, Gobierno y Jefatura del Estado, haciendo de esta una magistratura supraejecutiva.

Como ya señalé más atrás, la institución del refrendo ministerial de los actos del jefe del Estado ha tendido a trasladar, de hecho, las competencias de la Jefatura del Estado al Gobierno parlamentariamente responsable. Pero la mera titularidad formal de la supremacía de mando tiene tres consecuencias de gran importancia.

En primer lugar, a esa supremacía formal de mando, por parte muy significativa de la más autorizada doctrina se vincula la condición de «magistrado para la crisis», esto es, defensor político de la Constitución cuando fallan las restantes instituciones del Estado, sin que proceda ahora examinar las diversas construcciones doctrinales al efecto ${ }^{46}$.

De otra parte, el refrendo se entiende por doquier, salvo por la ucrónica doctrina española, como un acto complejo en el que concurren la voluntad del refrendante con la del refrendado ${ }^{47}$. Ello exige la colaboración del monarca o presidente en la formalización de aquellos actos que, aun siendo gubernamentales, como el poder reglamentario o el nombramiento de altos funcionarios, se formalizan por un acto del jefe del Estado que nadie puede suplir.

En fin, esta intervención del Jefatura del Estado, aun formal, exige que esta sea informada de lo que se le somete y pueda y deba examinarlo. Las famosas cajas rojas que diariamente el Gabinete británico hace llegar a la reina con documentación e información para su despacho es la expresión plástica de ese deber de información. Un deber de información que subsiste incluso en

46 Crisafulli (1958: 69).

47 Herrero de Miñón (1996: 22) y la bibliografía allí citada. En contra, véase González Trevijano (1998). 
aquellas constituciones que niegan al jefe del Estado monárquico, toda competencia gubernamental (por ejemplo, Suecia 1974, IG 5,1). Es ahí donde cabe ejercer más intensamente la función moderadora del jefe del Estado parlamentario, de advertir y animar. Si el deber gubernamental de información al jefe del Estado se convierte en un mero trámite formal, la función moderadora se esfuma.

Ello ha dado lugar a que - en paralelo a la atribución al jefe del Estado de competencias propias, incluso exentas del refrendo ministerial - se atribuyan al Gobierno, y concretamente a su presidente o primer ministro, competencias ajenas a la formalización por parte del jefe del Estado. En ello radica la autonomía institucional de ambas magistraturas.

Además, es de notar que la mayoría de las Constituciones parlamentarias atribuyen al jefe del Estado la Jefatura de las Fuerzas Armadas y una especial intervención en la acción exterior del Estado, una tendencia que se refuerza en los sistemas semipresidenciales, hasta constituir, en algunos de ellos, dominios reservados al monarca o presidente. Hacen excepción los casos de Japón y la República Federal de Alemania donde la experiencia de Weimar lleva a atribuir el mando de las Fuerzas Amadas al ministro de Defensa (art. 65a/ GG) y, en caso de Estado de Defensa (cf.art.115 a/ GG), al canciller (art. 115b/ GG).

La tradicional orientación de los jefes del Estado - especialmente los príncipes, pero también los presidentes de la República, al cultivo de la diplomacia al más alto nivel, fundamental en las relaciones internacionales hasta la I Guerra Mundial - se mantiene después, como hábito, por doquier existe un Ejecutivo bicéfalo. Pero son numerosas las constituciones que prevén expresamente el deber gubernamental de informar al jefe del Estado de las negociaciones internacionales, su protagonismo en el derecho de legación e, incluso, su coparticipación en el ejercicio del poder exterior del Estado.

En cuanto al mando militar que suele reconocerse al jefe del Estado parlamentario y semipresidencial, sin perjuicio de su posible delegación en un comandante en jefe para la guerra, ha evolucionado, más por razones técnicas que políticas, desde el mando operativo, ejercido todavía en la II Guerra Mundial, por los reyes de Noruega y Bélgica, hacia un mando eminente.

Ese mando eminente significa la despolitización de las Fuerzas Armadas y su condición de institución estatal y se concreta en situar al jefe del Estado a la cabeza de la jerarquía militar ${ }^{48}$, su presidencia y activa participación en los

48 Así ocurre en Suecia, donde el rey no tiene el mando supremo de los ejércitos, pero ostenta el más alto grado en los mismos y preside el Comité de Asuntos Exteriores elegido por la Dieta y que, junto con el Gobierno, analiza estas materias (IG 1974, art. 10,7). 
organismos superiores de la defensa nacional, y en su especial atención a la mejor dotación y organización de los ejércitos. La autonomía institucional del Gobierno responsable para dirigir la política de defensa y la Administración militar no puede llevarle a prescindir de estas competencias del jefe del Estado y la práctica comparada muestra su posible y eficaz articulación. La crisis francesa que puso fin a la IV República en 1958 mostró la eficacia de esta posición del jefe del Estado cuando el presidente Coty invocó, frente a los militares sublevados, su título, nada más que título, no ejercicio, de jefe de las Fuerzas Armadas que la Constitución de 1946 le atribuía.

\section{DEFENSA DE LA CONSTITUCIÓN}

La tutela institucional corresponde al jefe del Estado como defensor de la Constitución.

Fue Carl Schmitt quien, en $1929^{49}$, acuñó el concepto con relación al presidente del Reich, lo que inició una famosa polémica con Hans Kelsen sobre la defensa política o jurídica de la Constitución que no vamos a abordar aquí. Pero el concepto tuvo una proyección doctrinal menos dramática que la diseñada por su inventor. Mientras Schmitt construyó su concepto sobre el supuesto de la dictadura presidencial, así rezaba su famoso título de $1924^{50}$, en virtud de los poderes de excepción previstos en el art. 48 del texto de Weimar, autores de filiación francesa buscaron su fundamentación en las funciones de autentificación y formalización de los actos de Estado que, normalmente, corresponden al monarca o presidente.

En efecto, por limitadas que sean sus competencias, les corresponde la formalización de una serie de actos cuyo origen e, incluso, contenido están en la voluntad de terceros, sean estos las Cámaras o los ministros. Pues bien, su consideración como defensor de la Constitución da un contenido substantivo a estas atribuciones formales que dejan de ser meros actos debidos, como "si de estampar un sello se tratase», para utilizar una expresión famosa. Si el jefe del Estado ejerce una función análoga a la notarial, es lógico reconocerle, como es propio del notariado latino, la conformación jurídica de lo que el tercero, Gobierno o Asamblea, que solicita su preceptiva intervención propone. Así lo entendió la más autorizada doctrina con la siguiente argumentación ${ }^{51}$.

\footnotetext{
49 Schmitt (1929).

50 Schmitt (1924). Véase el parágrafo final.

51 Gordon (1931: 207).
} 
La Constitución puede ser violada por dos tipos de actos jurídicos: aquellos que se producen sin los requisitos constitucionalmente exigidos - ya sea la autoría, ya la competencia, ya el procedimiento- y aquellos que violan el orden material de valores inherente a la Constitución. Sirvan de ejemplo los supuestos de una ley no debidamente votada por las Cámaras parlamentarías o una disolución de estas cuando, por haberse declarado el estado de sitio, lo prohíba la Constitución o un decreto-ley que afectase gravemente a los derechos fundamentales.

El jefe del Estado, monárquico o republicano, al tomar posesión de su cargo, jura lealtad a la Constitución y, por lo tanto, cuando menos, no puede dar forma, sea expresando, sea dando fe de la constitucionalidad, de actos inconstitucionales. La no intervención del rey impediría su consumación. La facultad de impedir sería una eficaz técnica de defensa de la Constitución.

No se trata en tales casos del veto, suspensivo o incluso absoluto, que muchas constituciones otorgaban al rey o presidente como vieja herencia del constitucionalismo doctrinario ${ }^{52}$, sino de una consecuencia de su obligación de cumplir la Constitución que, lógicamente, le impide colaborar a su violación. Cuando se ha suprimido en el más reciente derecho penal la eximente de obediencia debida si se trata de los delitos contra la Constitución, sería absurdo exigir del jefe del Estado colaborar activamente a su expreso quebrantamiento. El jefe del Estado, en tal caso, no sigue un criterio político, sino estrictamente jurídico. La alternativa más depurada — adoptada, entre otras, por las vigentes Constituciones de Francia, la República Checa y Finlandia- consiste en atribuir en tales casos un reenvío de la cuestión por parte del jefe del Estado ante la correspondiente jurisdicción constitucional. Un reenvío que, para ser efectivo, ha de tener efectos suspensivos mientras no resuelva dicha jurisdicción.

Y aparte de esta defensa jurídica de la Constitución, compete al jefe del Estado, monárquico o republicano, en virtud de su juramento, un deber de defensa política. Una defensa política que, en circunstancias normales, se proyecta en el ejercicio de sus competencias de manera que sirvan al buen funcionamiento de las instituciones constitucionales.

\subsection{Prerrogativa regia británica}

Tales son los supuestos en los que los constitucionalistas británicos invocan el ejercicio de la prerrogativa regia, on Her own deliberated judgement. Una fórmula que merece un breve comentario.

52 Bompard (1909). 
Sabido es que, en virtud de las convenciones constitucionales establecidas a lo largo del siglo XIX, el monarca británico ha de actuar, en todo caso, de acuerdo con el consejo (advice) de los ministros responsables ante los Comunes. En consecuencia, de acuerdo con la versión vulgarizadora del constitucionalismo inglés que diera W. Bagehot ${ }^{53}$, el rey, tan solo, podía «advertir, animar y ser consultado» y, en consecuencia, «ser informado» por el Gobierno, pero estaba inhabilitado para cualquier actividad política autónoma.

Sin embargo, los más acreditados constitucionalistas británicos siguieron otro camino, al rescatar el concepto de prerrogativa regia definida como «los poderes remanentes en el rey sujetos a las leyes que haya aprobado el Parlamento en virtud de su supremacía». Una prerrogativa concretada en la designación y remoción del primer ministro, en la posible negación de la sanción regia a una ley votada en el Parlamento y en la discrecionalidad de la disolución del Parlamento y que siguen vivos y son utilizables para garantizar en casos de crisis, más o menos graves, el funcionamiento democrático del sistema. Esto es, el Gobierno de acuerdo con la voluntad del verdadero soberano: el pueblo.

Tal fue la tesis defendida por acreditados constitucionalistas de cuatro generaciones hasta el presente. Anson ${ }^{54}$ a fines del siglo XIX, sir Ivor Jennings ${ }^{55}$ en la década de los cincuenta, sir Vernon Bogdanor ${ }^{56}$, en la de los ochenta y Rodney Brazier ${ }^{57}$ de cara al siglo XXI. Los estudios realizados a la sombra del Partido Laborista para eliminar toda discrecionalidad en el ejercicio de la prerrogativa y alentados desde la misma Corte para descargar de trabajo a la reina, olvidando el proverbio de que vivir no es necesario, pero reinar sí lo es, culminaron en la New Agenda for Democracy. Labour's Proposal for Constitutional Reform de $1993^{58}$, cuyas propuestas, descartadas en la plataforma electoral laborista de 1997, nunca se llevaron a cabo, pero reconocieron la existencia de dichos poderes de prerrogativa.

Ha sido la Fixed-term Parliaments Act 2011 la que, en apariencia, ha eliminado la prerrogativa de disolución y convocatoria del Parlamento, no las otras $\operatorname{dos}^{59}$. Sin embargo, la más doctrina considera que dicha ley no ha

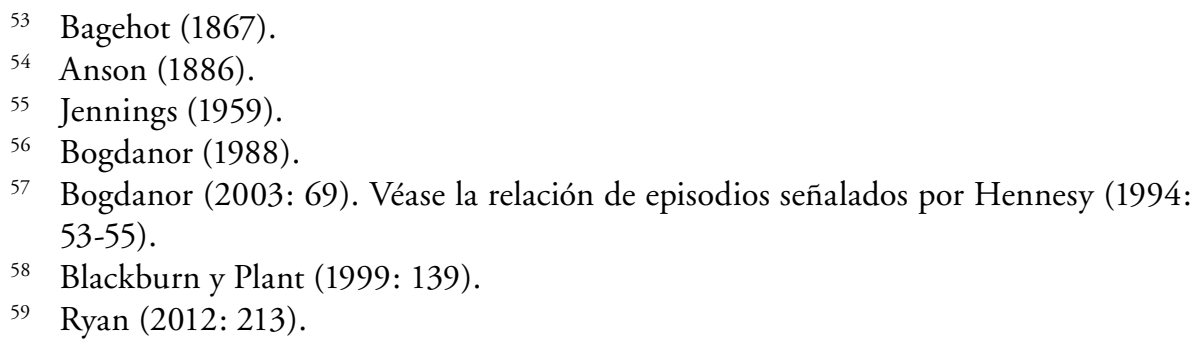


cancelado tal competencia regia, sino que la ha dejado en suspenso, pudiendo reactivarse en supuestos de crisis y restablecerse en el caso, no improbable, en que dicha ley del 2011 fuera derogada. La práctica política o la disolución anticipada de 2017 muestra la quiebra del sistema de 2011.

La difusión del constitucionalismo británico ${ }^{60}$, a través del Imperio, primero, y de la Commonwealth, después, y la recepción y racionalización de sus convenciones, incluso en las repúblicas parlamentarias, como es el caso de la India, han permitido avalar prácticamente tal interpretación. Los antiguos poderes de prerrogativa se ejercen por el jefe del Estado, el gobernador general o presidente según los casos, no de acuerdo con el consejo (advice) ministerial, sino según su propio y meditado criterio (on Her own deliberated judgement) ${ }^{61}$.

\subsection{Semipresidencialismo}

Lo dicho abre la vía a la consideración de los actos del jefe del Estado que Vedel denominó interconsitucionales. Porque el fiel cumplimiento de la Constitución que su juramento exige del jefe del Estado supone que las competencias que formalmente se le atribuyen se ejerzan de manera que las instituciones funcionen normalmente y que, cuando su funcionamiento se interrumpa, la normalidad sea restablecida.

La Constitución francesa de 1958 prevé las medidas de excepción (art. 58) y la fórmula ha sido seguida por muchas Constituciones parlamentarias.

Los sistemas semipresidenciales, cuyo paradigma es la V República Francesa, han racionalizado, esto es, han convertido en derecho estricto tales interpretaciones y, como antes dije, han hecho de los actos interconstitucionales competencias propias, como tales exentas de refrendo del jefe del Estado.

\subsection{La práctica belga e italiana como ejemplos típicos del parlamentarismo «clásico»}

Esta vía de fortalecimiento de la Jefatura del Estado puede detectarse también en sistemas netamente parlamentarios tanto republicanos como monárquicos. Sirvan de ejemplo los casos de Bélgica e Italia.

60 Schmitt (1964: 86).

61 Forsey (1943) y otros datos posteriores reunidos en mi obra Herrero de Miñón (1971: 147). En 1974, el gobernador general de Australia negó la disolución solicitada por el primer ministro porque consideró que existía una mayoría alternativa en el Parlamento. 
En Bélgica, los constituyentes de 1831 quisieron configurar «una monarquía republicana», atribuyendo al rey competencias expresamente tasadas y potenciando las del Parlamento ${ }^{62}$. Pero la evolución política del país y de su régimen ha matizado con la práctica las fórmulas constitucionales.

La personalidad del primer monarca Leopoldo I le convirtió en verdadero árbitro político de su reino, sin mengua de un régimen parlamentario, y otro tanto ocurrió bajo el reinado de su sucesor Leopoldo II, si bien este supo combinar su protagonismo internacional, tan ventajoso para la expansión colonial de Bélgica, con una escrupulosa imparcialidad en los más graves conflictos internos, especialmente los derivados de la guerra escolar entre liberales y católicos. La brillante conducta de Alberto I al frente de su ejército durante la I Guerra Mundial, cuyo paralelo en Noruega se dio en la II Guerra Mundial, incrementó muy mucho el prestigio de ambas monarquías. Ello dio lugar en Bélgica a una importante corriente doctrinal favorable a una afirmación extraconstitucional ${ }^{63}$ de la preeminencia regia, no compartida por la doctrina mayoritaria, pero que muestran las tendencias de una época cuyo extremo ejemplifican las fórmulas ensayadas en 1929 en España y Yugoslavia, atrás mencionadas.

La substitución, a partir de 1916 y hasta el presente, de un práctico bipartidismo por un multipartidismo que forzó los gobiernos de coalición, potenció lógicamente la figura del jefe del Estado como punto de referencia e impulsor de pactos y coaliciones.

La conducta de Leopoldo III en la II Guerra Mundial dio lugar a la crítica Question Royale que, sin embargo, se saldó, tras el referendo favorable al rey, con el consensuado Informe de 1949, «Sobre el ejercicio de los poderes regios» ${ }^{64}$. En él se reafirmó la monarquía parlamentaria y se declaró expresamente que, si bien el rey no puede obrar solo, sino siempre de acuerdo, expreso o tácito, con el Gobierno que asume la correspondiente responsabilidad, su actitud no es simplemente pasiva. En caso de insuperable desacuerdo con los ministros, son estos los que deben ceder o dimitir, remitiendo al electorado la decisión última, mediante la correspondiente disolución de las Cámaras ${ }^{65}$. La autoridad moral de Balduino I, «el confesor», reconocida por los partidos políticos, dio especial substantividad a esta interpretación que requiere, por parte de todos, la prudencia necesaria para evitar las situaciones de crisis constitucional.

62 Constitución de 1831, art. 78. Véase Senelle (1974).

63 Wodon (1939).

64 Moniteur Belge, 6 de agosto de 1949, pp. 7589 y ss.

65 Ibid., III, p. 7592 
La posterior evolución política y constitucional del país que ha llevado a permanentes y no muy estables gobiernos de coalición y, en último término, a la federalización de Bélgica, con la reforma constitucional de 1993, ha reforzado la función mediadora e integradora del rey. La adopción de la moción de censura constructiva en dicha reforma que, en principio, supone la abrogación de la importante designación regia del primer ministro no se ha puesto en práctica jamás ${ }^{66}$.

La reciente doctrina constitucionalista belga ${ }^{67}$ ha cifrado en tres conceptos esta función regia, aparte de la permanente consulta con el Gobierno y la actuación paralela, pero coordinada con este ${ }^{68}$.

Corresponde al jefe del Estado dar fe de los actos de Estado cuyo contenido fije el Parlamento, el Gobierno o la Magistratura y, como a un notario concienzudo corresponde, ha de asegurarse, previo el correspondiente examen, de la constitucionalidad formal y substancial del acto en cuestión. Le corresponde, en segundo lugar, exteriorizar y dar forma al acto de Estado. Le corresponde, en fin, en un supuesto de crisis, contribuir a la defensa de la Constitución, con todas sus competencias, incluso las militares ${ }^{69}$.

La tendencia al reforzamiento de las competencias del jefe del Estado parlamentario es aún más evidente en la República italiana.

La Asamblea Constituyente reunida en 1947, a la hora de diseñar la Jefatura del Estado republicana, optó por un presidente «ni demasiado fuerte ni demasiado débil $\gg^{70}$. Se quiso huir del precedente de Weimar, sin caer en la mera «magistratura moral» de la IV República Francesa, y fue importante el ejemplo de la Constitución española de 1931, por más que algunos analistas italianos traten de olvidarla. Baste pensar en la definición de la magistratura, en su forma de elección y en sus competencias.

Ahora bien, tanto en la elaboración del nuevo texto constitucional, según resulta de los trabajos constituyentes, como en su aplicación, fue determinante, por acción y reacción, la práctica del Estatuto albertino de 1848 anterior a la interpretación fascista desde 1923, es decir, una Constitución monárquica. Ya en los mismos debates de la Asamblea se invocó la denominada "prerrogativa presidencial ${ }^{71}$, calcada sobre la prerrogativa regia; y monárquico confeso fue el primer presidente constitucional de la República, Luigi Einaudi. Por otro lado,

\footnotetext{
66 Delpérée (2016).

67 Delpérée (1996: 43), Delpérée y Dupret (1990:19), Molitor (1996) y Stengers (1975).

68 Molitor (1996).

69 Moniteur Belge, 6 de agosto de 1949, p. 7595.

70 Caporali (2001: 1).

71 Tosato (1951: 336).
} 
una serie de convenciones constitucionales, detenidamente analizadas por la doctrina $^{72}$, han incrementado las competencias del presidente de la República y han configurado una "dirección constitucional» dirigida a la salvaguarda de los valores constitucionales y la garantía del correcto funcionamiento institucional, a cargo del presidente, junto a una «dirección política» correspondiente al Gobierno. La «dirección constitucional» se ejerce expresamente en lo que, siguiendo a Vedel, he denominado poderes interconstitucionales, pero también de manera más discreta, pero no menos eficaz. Así, la sustitución del primer ministro Berlusconi, que contaba con la confianza parlamentaria, por un candidato presidencial, cuya investidura parlamentaria estaba previamente asegurada, ha sido doctrinalmente interpretada como el último acto de esta extensión de las competencias presidenciales.

El presidente italiano, elegido por un colegio que suma a los parlamentarios los representantes de las regiones, es parte del ejecutivo y como tal tiene notables competencias administrativas cuidadosamente analizadas por la doctrina italiana ${ }^{73}$. Pero se configura en su génesis y, más aún, en su desarrollo práctico como una magistratura de garantía, tanto jurídica como política, de la fiel observancia y del normal funcionamiento de las instituciones constitucionales.

Así, se distinguen, entre sus competencias, las que se ejercen mediante actos formalmente presidenciales, sustancialmente presidenciales y sustancialmente complejos ${ }^{74}$. Las primeras son aquellas cuyo contenido es elaborado por otro u otros órganos, gubernamentales, parlamentarios o judiciales, pero que dan lugar a que el jefe del Estado, antes de su formalización, ejerza un derecho de examen, al menos para garantizar la constitucionalidad de estos. Los segundos, los sustancialmente presidenciales, son de competencia exclusiva del jefe del Estado, como los mensajes y, en general, los actos informales de exposición. Y los sustancialmente complejos, como el nombramiento del primer ministro o la disolución de las Cámaras, son de competencia presidencial, pero requieren la colaboración, en principio no vinculante, de terceros, como es el caso de la consulta preceptiva de los presidentes de las Cámaras para proceder a la disolución del Parlamento.

Es esta distinción la que permite clarificar los diferentes alcances, simétricos o asimétricos, del refrendo ministerial de todos los actos presidenciales, previsto en el art. 89 de la Constitución.

La categoría de acto debido que la doctrina española, fiel devota de la penúltima moda, sigue invocando a la hora de calificar las relaciones del jefe

72 Por todos, véase Branca (1978). En especial, Midiri (1988).

73 Santaniello (1990).

74 Vergotini (2006: 506). 
del Estado y el Gobierno parlamentario tiene una extensión harto reducida, puesto que no cubre más que el primero de los tipos señalados, esto es, los formalmente presidenciales y, aun así, el acto debido no es nunca automático, por el previo derecho de examen que se reconoce al presidente.

\section{CONCLUSIONES}

Esta larga exposición permite extraer del derecho y la práctica comparados las siguientes conclusiones:

1. Aunque la esencia del parlamentarismo es la responsabilidad política del Gobierno ante la Cámara, en las más importantes y estables democracias parlamentarias, el sistema supone un equilibrio, sin duda asimétrico, entre la Asamblea elegida y el jefe del Estado. Esto es lo que Redslob calificó de parlamentarismo auténtico. Ello contradice la tesis, según la cual, el parlamentarismo tiende desde el dualismo originario al monismo y reduce la Jefatura del Estado a una mera función representativa y simbólica, algo que también es importante.

2. Desde fines del siglo XVIII hasta el presente, la evolución del parlamentarismo y la correspondiente posición del jefe del Estado no han sido lineales. A sistemas dualistas en los que el jefe del Estado, rey o presidente, desempeñaba funciones muy activas (orleanismo) sucedió, en las constituciones de la primera posguerra, un auge del parlamentarismo monista y una capitidisminución cuando no desaparición de la Jefatura del Estado. Y, años después, como reacción, un fortalecimiento del ejecutivo en torno a las competencias del jefe del Estado, doble fenómeno que se repite tras la segunda posguerra, más por vía de mutación que de revisión constitucional.

3. La fórmula típica de este fortalecimiento de la Jefatura del Estado es, en las repúblicas, el semipresidencialismo, susceptible de diversas modulaciones, pero cuya característica fundamental es la autonomía institucional de la Jefatura del Estado que ostenta formalmente y ejerce una serie de competencias propias no sometidas a refrendo gubernamental. En paralelo a esa autonomía institucional del jefe del Estado, las constituciones semipresidencialistas reconocen una autonomía institucional del Gobierno parlamentariamente responsable que ostenta competencias propias que ejerce sin intervención el jefe del Estado, salvo ciertas materias, usualmente defensa y política exterior y un deber general de información hacia el jefe del Estado. 
En las monarquías se da un fenómeno paralelo, ya porque se mantenga viva la prerrogativa regia, sin perjuicio de la excepcionalidad de su utilización —constitucionalismo británico-, ya por una mutación convencional de la Constitución (caso belga).

En ambos supuestos, y al margen de la letra de los textos constitucionales, pero de acuerdo con su espíritu, el de los constituyentes cuando son recientes, el de la exégesis constitucional más solvente en todo caso, la Jefatura del Estado, monárquica o republicana, se configura como una magistratura de garantía de las formas y los valores constitucionales.

4. El refrendo es un acto complejo en el que concurren, refrendante y refrendado como exige el respeto hacia la autonomía institucional de uno y otro.

5. El jefe del Estado, parlamentario y, a fortiori, semipresidencial, representa la unidad y continuidad de este, garantiza en virtud de sus competencias interconstitucionales el funcionamiento de los poderes públicos y su sometimiento a la voluntad popular. Dichas competencias propias, que Vedel calificó de interconstitucionales, son, fundamentalmente, el nombramiento del Gobierno, sin perjuicio de requerir este la confianza de la o las Cámaras, la disolución de estas, la convocatoria del referéndum y la remisión de cuestiones ante el Tribunal Constitucional. El jefe del Estado es el defensor de la Constitución, tanto en situaciones de crisis como porque le corresponde su formalización y, con ello, acreditar, tras el debido examen, la constitucionalidad de los actos de Estado a cargo de las asambleas y del Gobierno.

\section{Bibliografía}

Alcalá-Zamora y Torres, N. (1931). Los defectos de la Constitución española de 1931. Madrid: R. Espinosa.

Anson, W. R. (1886). Law and Custom of the Constitution. Oxford: Clarendon Press.

Bagehot, W. (1867). The English Constitution. London: Oxford.

Blackburn, R. y Plant, R. (eds.) (1999). Constitutional reform, the Labour Government' constitutional reform agenda. London: Longman.

Bogdanor, V. (1988). The monarchy and the constitution. Oxford: Clarendon Press.

— (2003). The monarchy. En V. Bodganor (ed). The British Constitution in the twentieth century. Oxford: British Academy.

Bompard, R. (1909). Le veto du Président de la République et la sanction royale. Paris: Arthur Rousseau Éditeur.

Branca, G. (ed.) (1978). Commentario della Costituzione. Il presidente de la Repubblica, vol. I (arts. 83-87). Bologna: Zanichelli Editore; Roma: Società Editrice del Foro italiano. 
Brunner, G. (1988). Constitutional models in communist States. A typological overview. En M. Peláez (ed). European Constitutional Law. Derecho Constitucional Europeo. Homenaje a F. Valls i Taberner (pp. 2079-2128). Barcelona: Pompeu Fabra.

Caporali, G. (1999). Il presidente della Repubblica e l'emanazione degli atti con forza di legge. Turin: Giappichelli Editore.

- (2001). Il presidente della Repubblica e l'emanazione degli atti con forza di legge. Turin: Giappichelli.

Carlsson, S. y Rosén, J. (1961). Svensk Historia I. Stockholm: Bonnier.

Colliard, J. C. (1978). Les Régimes parlementaires contemporains. Paris: Presses de Science Po.

Crisafulli, V. (1958). Aspetti problematici del sistema parlamentare vigente en Italia, Jus, 1958, 9, 151-190.

Smith, S. (1964). The New Commonwealth and its Constitutions. Oxford: Stevens.

Delpérée, F. (1996). La fonction du Roi. Pouvoirs : Revue française d'études constitutionnelles et politiques, 78, 43-54.

- (2016). La formation du Gouvernement. Texte et Contexte. Ponencia presentada en Rouen en junio de 2016.

- y Dupret, B. (1990). Le Roi des Belges. Pouvoirs, 54, 15-24.

Dendias, M. (1932). Le renforcement des pouvoirs du Chef de l'Etat dans la démocratie parlementaire. Paris: Boccard.

Díez del Corral, L. (1998). El liberalismo doctrinario, Obras completas. Madrid: Centro de Estudios Políticos y Constitucionales.

Duguit, L. (1903). L'Etat, les gouvernants et les agents. Paris: Albert Fontemoing.

Duverger, M. (1970). Institutions politiques et droit constitutionnel. Paris: PUF.

- (1986). Les régimes semiprésidentiels. Paris: LGDJ.

Ehmke, H. (1953). Grenzen der Verfassungsänderung. Berlin: Duncker und Humblot.

Fawcett, J. (1963). The Commonwealth and international law. Oxford: Steven and Sons.

Fernández Segado, F. (1986). Las constituciones históricas españolas. Madrid: Civitas.

Fioravanti, M. (2002). Constitucionalismo. Experiencias históricas y tendencias actuales. Madrid: Trotta.

Forsey, E. (1943). The royal power of dissolution of parliament in the British Commonwealth. Toronto: Oxford University Press.

García Álvarez, M. (1978). Construcción del comunismo y Constitución. León: Colegio Universitario de León.

Ghisalberti, C. (1974). Storia constituxionale d'Italia. Roma-Bari: Laterza.

Gicquel, J. (1968). Essai sur la pratique de la Vème République, Bilan d'un septennat. Paris: LGDJ.

Gomes Canotilho, J. y Moreira, V. (1964). Os poderes do presidente da Republica. Coimbra: Ed. Coimbra.

González Trevijano, P. (1998). El refrendo. Madrid: Centro de Estudios Políticos y Constitucionales.

Gordon, E. (1931). Les nouvelles constitutions européennes et le rôle du Chef de l'État. Paris: Sirey.

Gutan, M. (2012). Romanian semi-presidentialism in historical context. Revista Română de Drept Comparat, 212, 275-303. 
Hennesy, P. (1994). The Throne behind the Power. The Economist, 24.

Herrero de Miñón, M. (1971). Nacionalismo y constitucionalismo. El derecho constitucional de los nuevos Estados. Madrid: Tecnos.

- (1986). Una raíz del Estado autoritario: los Consejos del Antiguo Régimen. En C. Moya Valgañón y L. Rodríguez Zúñiga (coords.). Libro homenaje a José Antonio Maravall (pp. 305-318). Madrid: Centro de Investigaciones Sociológicas.

— (1996). El refrendo, artículo 64. En Ó. Alzaga (ed.). Comentarios a la Constitución española de 1978 (t. V, pp. 279-308). Madrid: Edersa.

Jellinek, G. (1980). Teoría general del Estado. Buenos Aires: Albatros.

Jennings, I. (1959). Cabinet Government. Cambridge: Cambridge University Press.

Jovanovitch (1930). Le régime absolu yougoslave institué le 6 janvier 1929. Paris: P. Bossuet.

Kaltefleiter, W. (1970). Die Funktionen des Staatsoberhauptes in der parlamentarischen Demokratie. Colonia: Springer Fachmedien Wiesbaden.

Kelsen, H. (1919). Die Verfassungsgesetze der Republik Deutschösterreich. Vienna: F. Deuticke.

- (1979). Teoría general del Estado (Luis Legaz Lacambra trad.). México: Editora Nacional.

Kimminich, O. (1967). Das Staatsoberhaupt in der parlamentarischen Demokratie. Veröffentlichungen der Vereinigung der Deutschen Staatsrechtslehrer, 25, 2-256.

Kollreutter, O. (1921). Das parlamentarische System in den deutschen Landesverfassungen. Tübingen: Mohr.

Le Bradizec (1998). René Capitant, Carl Schmitt: crise et réforme du parlementarisme. Paris: L'Harmattan.

Leissner, W. (1958). Le Président de la République et le Gouvernement dans la Constitution de Bonn. Revue du Droit Public, 6.

Loewenstein, K. (1949). Étude de Droit Comparé sur la Présidence de la République. Revue du Droit Public et de la Science Politique, 65, 153-168.

— (1965). Teoría de la Constitución. Barcelona: Ariel.

Lukas, K. (1920). Die organisatorischen Grundgedanken des neuen Reichverfassung. Tübingen: J. C. B. Mohr.

Midiri, M. (1988). La controfirma ministeriale nel sistema dei rapporti tra presidente della Repubblica e Governo. Padova: CEDAM.

Mirkine Guetzevitch, B. (1928). Constitutions de l'Europe nouvelle. Paris: Delagrave.

- (1930). La révision constitutionnelle en Autriche. L'Europe Nouvelle, 623.

- (1930). Les Constitutions Européennes. Paris: PUF.

(1931). Las nuevas constituciones del mundo. Madrid: Editorial España.

(1935). Le parlementarisme sous la Convention nationale. Revue du Droit Public et de la Science Politique, 42 (52), 671-700.

- (1952). De la separation des pouvoirs. París: Sirey.

Molitor, A. (1966). La Fonction Royale en Belgique. Bruxelles: CRISP.

Pérez Royo, J. (1984). Jefatura del Estado y democracia parlamentaria. Revista de Estudios Politicos, 39, 7-27.

Peska, Z. (1930). Après dix années, le développement de la Constitution Tchécoslovaque. Revue du Droit Public, 3.

Poyulicki (1921). La Constitution de la République de Pologne de 17 mars 1921. 
Prévost-Paradol, A. (1868). La France Nouvelle. Paris: Michel Levy Frères.

Redslob, R. (1918). Die parlamentarische Regierung in ihrer wahren und ihrer unechten Form: eine vergleichende Studie über die Verfassungen von England, Belgien, Ungarn, Schweden und Frankreich. Tübingen: J. C. B. Mohr.

Robinson, J. (1928). Der litauische Staat und seine Verfassungsentwicklung. Jahrbuch des öffentlichen Rechts der Gegenwart, 6, 295-315.

Rodríguez Artacho, S. (2003). La monarquía japonesa. Madrid: Centro de Estudios Políticos y Constitucionales.

Rolnik, H. (1927). Die baltischen Staaten Litauen, Lettland und Estland und ihr Verfassungsrecht. Leipzig: Robert Noske.

Röpke, F. (1922). Von Gambetta Bis Clemenceau: Funfzig Jahre Franzosischer Politik Und Geschichte. Stuttgart: Deutsche Verlags-Antstalt.

Ryan, M. (2012). The Fixed-term Parliaments Act 2011. Public Law, 2, 213-221.

Santaniello, G. (ed.) (1990). Trattato di diritto Amministrativo. Padova: CEDAM.

Schmitt, C. (1964) [1924]. Die Diktatur. Berlin: Duncker und Humblot.

— (1929). Der Hüter der Verfassung. Archiv des öffentlichen Rechts, 16, 161-237.

Selejan-Gutan, B. (2016). The Constitution of Romania: A contextual analysis. Oxford: Hart.

Senelle, R. (1974). La Constitution belge commentée. Belgique: Ministère des affaires étrangères, du commerce extérieur et de la coopération du développement.

Smend, R. (1928). Verfassung und Verfassungsrecht. Berlin: Duncker und Humboldt.

Stengers, J. (1974). L'action du roi en Belgique depuis 1831. Pouvoir et influence. Paris: Louvain.

Stubbs, W. (1898). The constitutional history of England. Oxford: Clarendon Press.

Trentin, S. y Bonnecase, J. (1929). Les transformations récentes du droit public italien de la Charte de Charles-Albert à la création de l'État fasciste. Paris: M. Giard.

Varela Suanzes-Carpegna, J. (2012). Constituciones y leyes fundamentales. Madrid: Iustel.

- (2016). Estudio preliminar. En W. Bagehot. La Constitución inglesa. Madrid: Centro de Estudios Políticos y Constitucionales.

Vedel, G. (1964). Vers le régime présidentiel. Revue Française de Science Politique, 14, 20-32. Vernet, R. (1922). Le pouvoir exécutifen Droit Constitutionnel tchécoslovaque. Genève: Cahors.

Wodon, L. (1939). Sur le rôle du Roi comme Chef de l'Etat dans le cas de défaillances constitutionnelles. Bulletin de la classe des lettres et des sciences sociales et politiques de l'académie royale de Belgique, série 5, 27.

Zolo, D. (1974). La teoría comunista dell'estinzione dello Stato. Bari: De Donato. 